\title{
New Focus on the Tales of the Earth-Legacy Cores Redistribution Project Completed
}

by John Firth, Lallan Gupta, and Ursula Röhl

doi:10.2204/iodp.sd.7.03.2009

Scientific drilling for marine cores began in 1968 under the auspices of the Deep Sea Drilling Project (DSDP), whose initial discoveries included salt domes on the sea floor and formation of oceanic crust by sea-floor spreading along the mid-ocean ridges rift zone. Analyses of cores in various laboratories all over the world provided key information toward a better understanding of Earth's past, present, and future including the geology of the sea floor, evolution of the Earth, and past climatic changes. With an eye towards future development of analytical tools for core-based research, it was important to maintain cores in as close to their original condition as possible for the years to come. This led to the establishment of large repositories curating cores at $4^{\circ} \mathrm{C}$, conducting sub-sampling, and facilitating non-destructive observation of cores while following well-defined curation policies.

Collection management of scientific ocean drilling cores has always been a shared responsibility. Beginning with DSDP, drill cores from the world's oceans were all stored in the United States and separated geographically into two regions. The East Coast Repository (ECR) at Lamont-Doherty Geological Observatory in Palisades, New York was responsible for taking care of cores from the Gulf of Mexico, Atlantic Ocean, Southern Ocean (loosely defined as south of $60^{\circ} \mathrm{S}$ latitude) and their peripheral seas, whereas the West Coast Repository (WCR) at Scripps Institution of Oceanography in San Diego, California was responsible for cores from the Pacific and Indian Oceans and their peripheral seas. At the end of fifteen years of DSDP operations in 1983, the $96 \mathrm{~km}$ of recovered core were almost evenly split between the two DSDP repositories.

With the advent of the Ocean Drilling Program (ODP), the WCR was completely filled. The Gulf Coast Repository (GCR) was built at Texas A\&M University in College Station to store new cores from the Pacific and Indian Oceans, and ECR continued to set up new core storage available for its portion of the globe. A satellite repository of the GCR at the New Jersey Geological Survey/Rutgers University stores land-based cores from ODP Legs 150X and 174AX drilled from 1993 through 1997; these are scientifically related to the ODP Leg 150 and 174A marine cores taken off the New Jersey margin. In 1994, space at the ECR was becoming limited, and the international partners of ODP requested a new repository in Europe, closer to many of the scientists
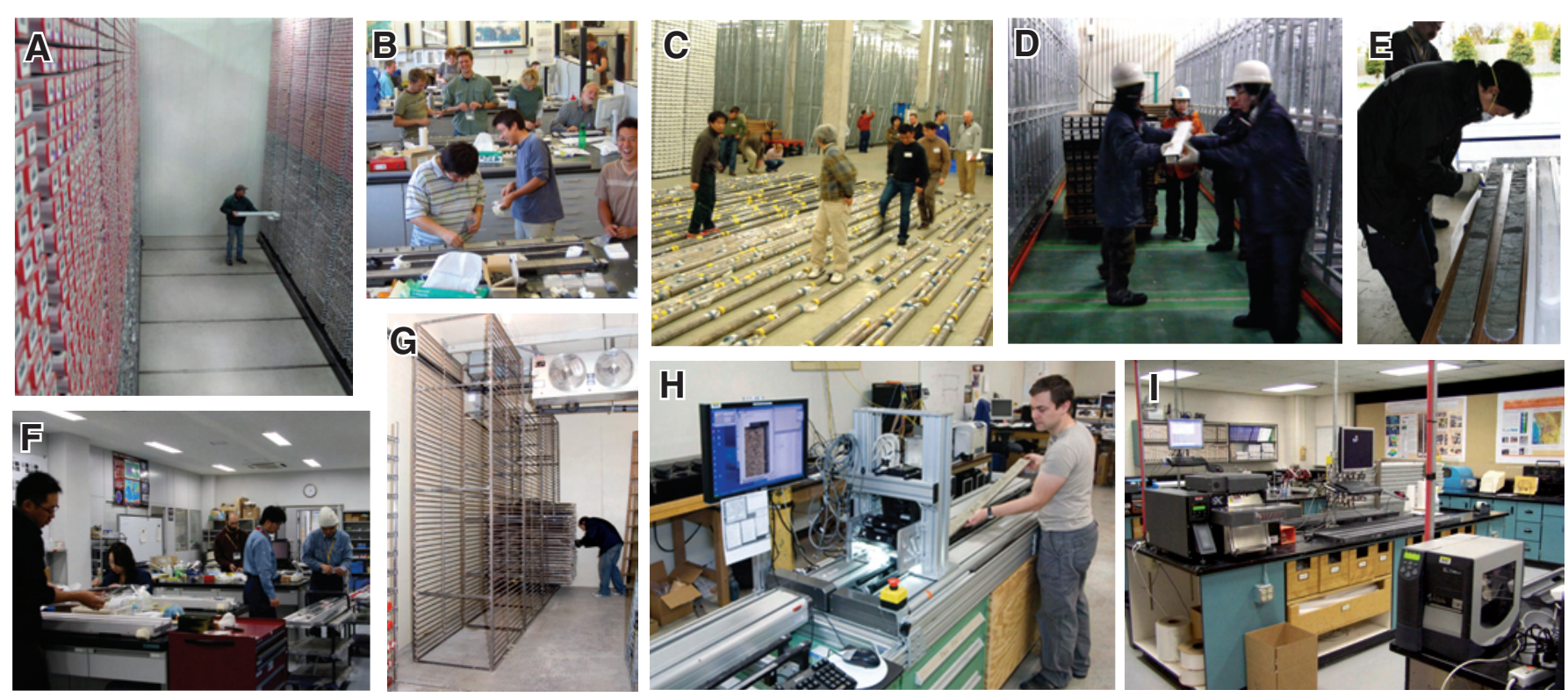

The New Repositories in Action: [A] The 5.5-m-high movable core racks in the BCR (@) MARUM). [B] On-shore core description and sampling party for IODP Expedition 307 at the BCR (@ IODP-BCR). [C] IODP Expedition 310 ("Tahiti Sea Level") Onshore Science Party at BCR: cores laid out in the reefer before the splitting, analyses, and sampling started. (@ IODP-ESO). [D] First legacy cores arrive at the KCC (@ IODP-JPIO). [E] IODP NanTroSEIZE Stage 1A core sections (C IODP-JPIO). [F] Sampling of the NanTroSEIZE Stage 1A cores at the KCC (C IODP-JPIO). [G] New high density core racks in the GCR for storage of the oldest DSDP cores beginning with Leg 1 (C) IODP-USIO).[H] Legacy core being reanalyzed with newly developed digital imaging system for the JOIDES Resolution, in the new GCR lab facility (@) IODP-USIO). [I] New GCR sampling station with automated sample bagging machine (@ IODP-USIO). 
outside of North America. The Bremen Core Repository (BCR) in Bremen, Germany thus began operations by taking over the ECR's Atlantic/Southern Ocean responsibilities starting with ODP Leg 151.

After twenty years of ODP operations, another $222 \mathrm{~km}$ of core had been collected, with the ECR containing roughly $75 \mathrm{~km}$, the WCR still at roughly $50 \mathrm{~km}$, the GCR at $120 \mathrm{~km}$, and the BCR at $75 \mathrm{~km}$. These DSDP and ODP cores are now referred to as 'legacy' cores.

In the early phase of the Integrated Ocean Drilling Program (IODP) in 2004, several new developments along with concerns of the scientific community provided an impetus to re-evaluate the core storage strategy for both legacy and new cores.

The oldest cores stored at the WCR and ECR were in relatively less demand by the international scientific community than the more recent cores at the GCR and BCR. This reflects a normal trend for all cores, where the greatest usage in terms of sampling usually occurs within the first five years, after which usage steadily declines. The cost of maintaining these low-usage core collections at their original locations was quite high compared to the cost of the more recent collections, simply because of the need to pay for rental space, utilities for cold storage, and complete core sampling labs and staff at these facilities. It was apparent that combining these old collections with the newer ones would reduce costs.

In early 2005 the BCR collection was moved from the former harbor area of Bremen to the MARUM-Center for Marine Environmental Sciences building on the campus of Bremen University. The new core reefer in the MARUM building and additional laboratory and office space greatly facilitate core sampling and analysis. The infrastructure of the MARUM and of the Faculty of Geosciences, University of Bremen, features a unique set of high capacity facilities, for both the initial handling and for highly sophisticated analyses of marinesediments, including three XRF core scanners and an X-ray CT scanner. The new BCR has approximately tripled the capacity of the old facility.

In April 2004, JAMSTEC
(Japan Agency for
Marine-Earth Science and
Technology) and Kochi
University established a
new marine core research
center (nicknamed Kochi

Core Center, or KCC, in June 2006) on the Monobe campus of the university in Nankoku City, Japan. The center has a movable rack system for core storage, a number of large liquid $\mathrm{N}_{2}$ freezers for the storage of microbiological and hydrate samples, and a large set of state-of-the-art analytical equipment including X-ray CT and XRF core scanners. Curation of the IODP and legacy cores at KCC is managed by JAMSTEC, while the analytical facility is maintained through collaboration of the university and JAMSTEC.

Texas A\&M University committed to ensuring greater core storage capacity and to creating a shore-based analytical laboratory facility adjacent to the GCR as part of its contribution to the IODP. The laboratory space was used in 2007 and 2008 for development of new shipboard analytical tools for the newly refurbished DV JOIDES Resolution, and it is ready for installation of its first instrument, an XRF core scanner, in the spring of 2009 . The GCR has nearly $100 \mathrm{~km}$ of additional core storage capacity, contains some additional oceanographic cores, and serves also as the core storage site for the San Andreas Fault Observatory at Depth project of the International Continental Scientific Drilling Program (ICDP).

IODP became a multi-platform operation with the construction of the $D V$ Chikyu and with the conception of ECORD's Mission Specific Platforms (MSP) for drilling projects not achievable using either the U.S. non-riser $D V$ JOIDES Resolution or Japan's riser DV Chikyu.

The addition of analytical facilities complementing the core repositories was an important advancement for improving service to the community. For example, the facilities can be utilized to complete analytical work not carried out on board. MSPs are normally not equipped with the laboratory facilities that scientists are accustomed to on other IODP drilling vessels. The Onshore Science Party (OSP) at BCR takes place after MSP offshore operations (which capture, at

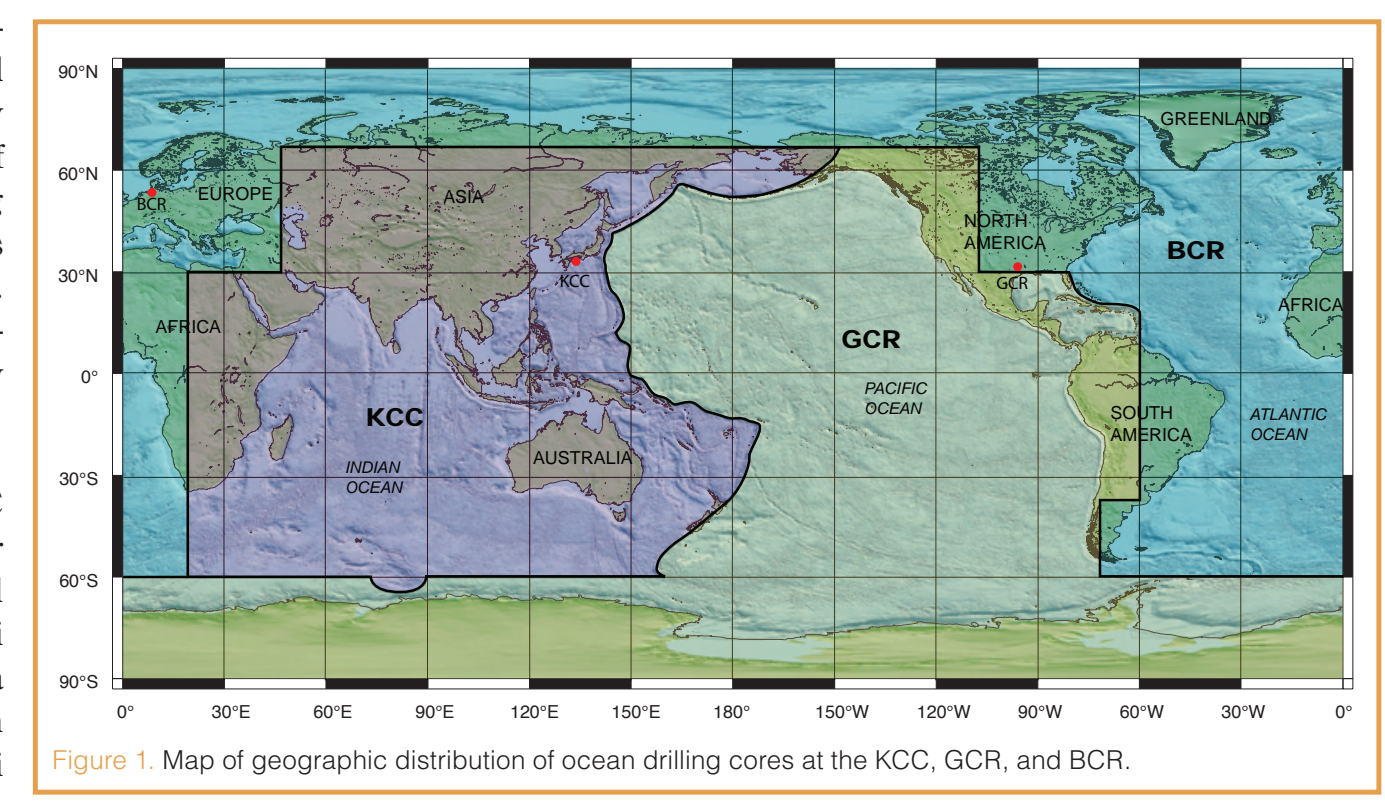


a minimum, mostly ephemeral properties) are completed. At the OSP in Bremen, cores are split and scientists have their first opportunity to study, analyze, and sample the cores in detail. The utilization of the facility for personal research also provides the advantage of minimal deterioration in the core sample quality, which would otherwise be a concern (e.g., contamination and rise in temperature during shipment of samples from a repository to a researcher's laboratory) especially for microbiological research.

All of these new developments were discussed among the Implementing Organizations (IOs), their funding agencies, and Integrated Ocean Drilling Program-Management International (IODP-MI). Consequently a decision was made that the storage of cores from the world's oceans should now reflect the three-way partitioning of drilling responsibilities in the new program. A project was approved and funded to close the ECR and WCR, consolidate their cores with those of the BCR and GCR, and re-distribute the collections among the three primary repositories to a new geographic system that is fairly balanced in terms of volume of core material, and which would include future IODP cores. After two years of work, about two-thirds of the DSDP/ODP core collection $(>200 \mathrm{~km}$ ) were moved, and the ECR and WCR were both officially closed on 30 September 2008. In addition, the first phase of IODP drilling recovered more than $15 \mathrm{~km}$ of new cores between 2004 and 2008. The current status of all scientific ocean drilling cores at the three IODP repositories (Fig. 1) is as follows:

- The GCR stores cores from the Pacific Ocean plate, the Southern Ocean south of $60^{\circ} \mathrm{S}$ latitude (except Kerguelan Plateau), the Gulf of Mexico, and the Caribbean Sea. It presently houses over $109 \mathrm{~km}$ of core.

- The BCR stores cores from the North and South Atlantic, the Mediterranean and Black Seas, and the Arctic Ocean. It now houses over $140 \mathrm{~km}$ of core.

- The KCC stores cores from the Indian Ocean and marginal seas, as well as from the western and northern marginal seas of the Pacific region, defined by the plate boundaries that extend from the Aleutian Trench to the Macquarie Ridge. It now houses over $85 \mathrm{~km}$ of core.

This new disposition of cores not only renders a change of locations, but also provides an opportunity to extend the usefulness of even the oldest drill cores by making them easily available to new non-destructive analytical systems that did not exist when many of these cores were first obtained. Therefore, the consolidation of old and new cores from similar regions within three well-balanced core storage and analytical facilities around the world is intended to enhance the use of this vast and still growing collection. After completion of this gigantic moving project, the curatorial staff at all three repositories are now ready to provide improved service to the international scientific community, including that in the Asia-Pacific region.

\section{Acknowledgements}

We would like to thank all of our staff at the GCR, WCR, ECR, BCR, and KCC for the smooth team effort across continents in efficiently getting through this enormous piece of work in less time while reducing the risk for the cores involved. Thanks in particular go to: Gar Esmay, Bruce Horan, Susan Andershock, Yasmin Yabyabin, Helene Gould, Steven Prinz, Roy Davis, Ted Gustafson, Phil Rumford, Walter Hale, Alex Wülbers, Holger Kuhlmann, Vera Lukies, Toshio Hisamitsu, and Satoshi Hirano.

\section{Authors}

John Firth, IODP-USIO, 1000 Discovery Drive, College Station, Texas 77845, U.S.A., e-mail: firth@iodp.tamu.edu.

Lallan Gupta, IODP-JPIO, Kochi Institute for Core Sample Research, Japan Agency for Marine-Earth Science and Technology (JAMSTEC), B200 Monobe, Nankoku, Kochi 783-8502, Japan, e-mail: gupta@jamstec.go.jp.

Ursula Röhl, Bremen Core Repository (BCR), MARUMCenter for Marine Environmental Sciences at Bremen University, Leobener Strasse, 28359 Bremen, Germany, e-mail: uroeh1@marum.de.

\section{Related Web Links}

DSDP: http://www.deepseadrilling.org

ODP: http://www-odp.tamu.edu

IODP: http://www.iodp.org

SEDIS: http://sedis.iodp.org/front_content.php

BCR: http://marum.de/en/IODP_Core_Repository.html

ECORD: http://www.ecord.org

GCR: http://iodp.tamu.edu/curation/gcr/index.html

KCC: http://www.kochi-core.jp/en/index.html

Rutgers Satellite Repository: http://geology.rutgers.edu/ corerepository.shtml

ICDP-SAFOD: http://safod.icdp-online.org

Access data and samples: http://www.iodp.org/ weblinks/Tasks-Scientists/Request-Access-to-Samples/ 